\section{EMBRYAIDDLE \\ Aeronautical University}

SCHOLARLY COMMONS

\section{International Journal of Aviation,} Aeronautics, and Aerospace

\title{
In-flight Wingtip Folding: Inspiration from the XB-70 Valkyrie
}

\author{
Gaétan X. Dussart \\ Cranfield University, g.x.dussart@cranfield.ac.uk \\ Mudassir Lone \\ Cranfield University, m.m.lone@cranfield.ac.uk \\ Ciaran O'Rourke \\ Airbus Ltd, ciaran.orourke@airbus.com \\ Thomas Wilson \\ Airbus Ltd, thomas.wilson@airbus.com
}

Follow this and additional works at: https://commons.erau.edu/ijaaa

Part of the Aeronautical Vehicles Commons, Applied Mechanics Commons, and the Aviation and Space Education Commons

\section{Scholarly Commons Citation}

Dussart, G. X., Lone, M., O'Rourke, C., \& Wilson, T. (2019). In-flight Wingtip Folding: Inspiration from the XB-70 Valkyrie. International Journal of Aviation, Aeronautics, and Aerospace, 6(3). https://doi.org/ 10.15394/ijaaa.2019.1343

This Article is brought to you for free and open access by the Journals at Scholarly Commons. It has been accepted for inclusion in International Journal of Aviation, Aeronautics, and Aerospace by an authorized administrator of Scholarly Commons. For more information, please contact commons@erau.edu. 


\section{Introduction}

To help develop future aircraft technologies, the authors investigated past developments and applications in the field of folding wingtips for inspiration, focusing on the XB-70 Valkyrie. Arguably the most iconic example of folding wingtip capable vehicle, it included the largest moving lifting surfaces ever flown and provides a good insight on the actuator and systems requirement for wingtip folding.

Following a justification for incremental aircraft design changes, the authors introduce past and on-going developments in folding wingtip systems for large civil aircraft. A quick overview of the iconic XB-70 supersonic bomber is given, partly to identify key motivations and benefits in the implementation of the folding wingtips. A review of the gathered and derived data regarding the actuation system is given specifically in terms of size, weight, and actuation capability. With such results in hand, a comparison against spatial and loads requirements of a set of conventional tubular swept wing aircraft wings is made to assess the scalability of the system to civil applications. The paper concludes with a general discussion on the applicability of these results and impact on the flared folding wingtip design considered for loads alleviation (Castrichini et al., 2016; Dussart, Lone, \& O'Rouke, 2019; Wilson et al., 2017).

\section{The Case for Incremental Aircraft Geometry Changes}

Despite well knowing that High Aspect Ratio Wings (HARW), along with other disruptive aircraft designs such as box or blended wings, have overall better aerodynamic performance than conventional swept wing designs, large civil aircraft manufacturers have been unable to deploy such designs into service. This can be explained by multiple limitations, the main one being due to the type and technology in materials used. Development in manufacturing and design of composite wings have been at the heart of serious efforts and progress throughout the industry lately. Another major limitation lies in aircraft operating infrastructure capabilities. A new design cannot expect the global airport infrastructure and ground operating procedure to change and adapt in order to accommodate it. Such a scenario is clearly economically non-viable. One vibrant example of this can be found in the rail industry, with the development of the hover train by Jean Bertin's Aerotrain in 1960's France. Despite having demonstrated benefits over the existing rail system (especially at high speed), the hover train had to compete with the already well established and mostly incompatible infrastructures where they existed. Competition against the TGV which relied on the conventional rail system ultimately led to the prototypes being stored away. Undeniably, this highlights that adapting new ideas to match complex economic, political and environmental issues is easier than having the existing world adapt to new revolutionary ideas which in turn justifies an incremental engineering approach. It can be argued that in the case of products meeting new growing market demands, the operational environment or infrastructures can be modified as needed. Such was the case with the Airbus 
A380, introduced to meet previously uncovered market shares, and which led to costly yet required changes in infrastructures where the aircraft would become successfully operated. However, the reader should note the recent decision to stop production of this aircraft, largely ahead of original plans. Ultimately, economics are what define the success of a solution. This includes safety, passenger capacity, investments and political struggles. Whilst some may see this as a rather defeatist view of innovation, with limitations and hindrance being set by elements independent from the engineering feasibility incremental changes are a safeguard against a wasting of resources and energy, and help engineers truly understand complex problems in details, favouring technological expertise and, most importantly in aviation, safety.

Therefore, aircraft designers have mainly followed an incremental development route, leading to the now conventional tubular swept wing aircraft design with aircraft ground operations, infrastructure and spatial limitations on aircraft wing span being significant parameters in aircraft general design and more specifically wing shape and geometry. It appears, however, that engineers have pushed the aerodynamic performances of their designs to operational limits. Arguably, the use of sharklets and fixed wingtip extensions are the results of attempts to further optimise aerodynamic performances with aircraft structural and ground operational limitations. Nowadays, engineers are considering adapting the wing shape of large civil aircraft during ground operations to unlock the potential of higher aspect ratio wings without disrupting the current ground operational and infrastructural practices.

\section{Existing Ground Folding Technologies}

Ground folding was historically used as an effective way to reduce the aircraft wing span dimensions when operated on aircraft carriers, in both fixed and rotary winged vehicles. As only a limited fixed space can be allocated per aircraft to maintain fleet size and operational levels, engineers are forced to include these ground morphing devices to maintain vehicle performance whilst ensuring the aircraft meet market demands. Such systems saw great success as early as the 1940's with the iconic F4U Corsair and are still used today on navybased aircraft variants such as the Lockheed Martin F-35C.

Facing similar concerns, and undoubtedly inspired by these proven systems, aircraft designers are now considering the implementation of similar ground wing span reduction strategies on large civil aircraft. Evidence of this can be found in the Boeing 777-X illustrated in Figure 1 with its now certified ground folding wingtip system, and the Boeing SUGAR concept (Bradley, Allen, \& Droney, 2014) pictured in Figure 2. Aircraft size limitations, dictated by airport infrastructures, could then be virtually exceeded by implementing these folding systems, and therefore be operated within the same infrastructures as their predecessors. This leads to limited infrastructure changes and increases in operational costs to airports and airlines when replacing the outdated and less profitable fleet. Nonetheless, the folding device in turn brings a number of additional complications in design, maintenance, operations, and an obvious 
weight (and therefore performance) penalty from the device itself which can be evaluated using the Breguet range equation (Hayes, Lone, Whidborne, \& Coetzee, 2017). Undeniably, the negative impact of the ground folding system weight, not used once in flight, could be reduced if it could also be used in-flight and proven to bring loads alleviation, stability augmentation or control benefits.

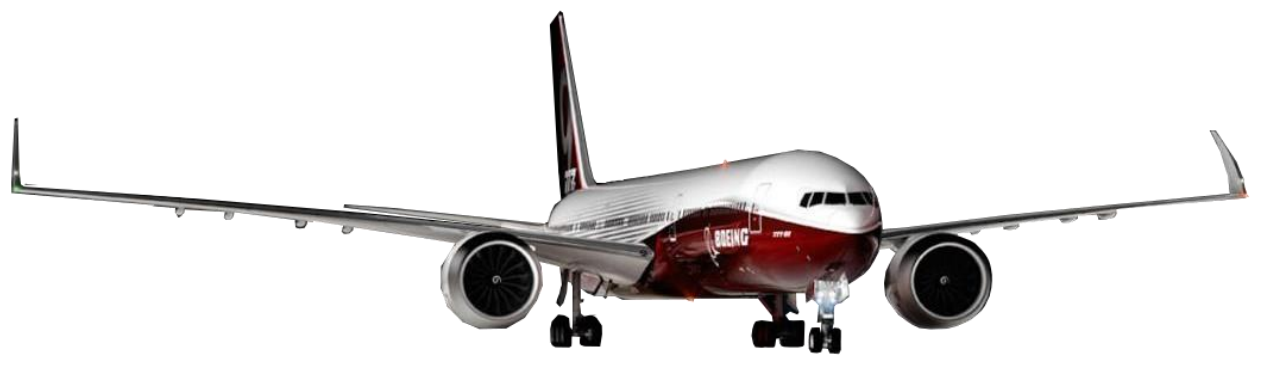

Figure 1. Boeing 777-X.

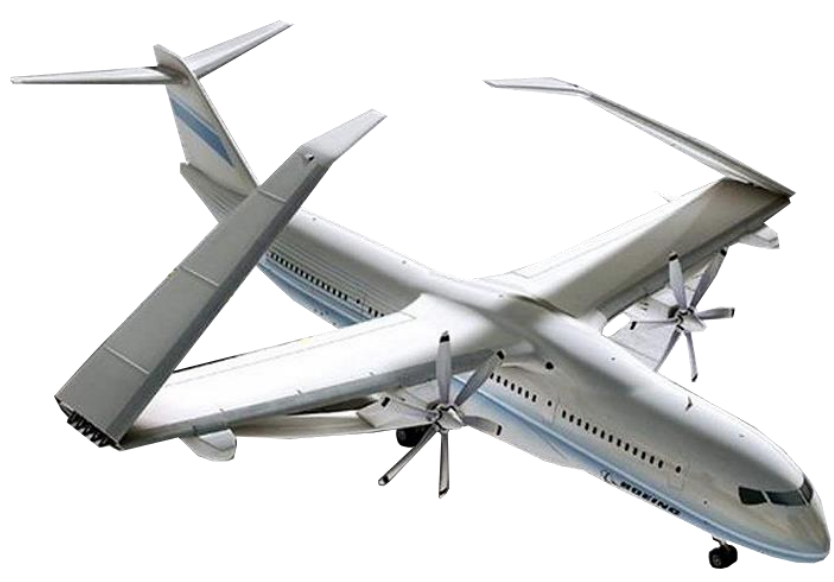

Figure 2. Boeing SUGAR III.

\section{In-flight Wingtip Folding Development}

Of course, the principle of changing the aircraft shape in-flight, or morphing, is hardly new. It can be traced back to the first flying machines, such as those sketched by Ader for his Aole aircraft concepts from 1890 or the early powered glider flights of the Wright brothers in 1903. But wing warping and other attempts at morphing quickly became marginal in aircraft development, as human flight made its first steps in history though military applications, quickly requiring strong, fast and more reliable airframes. A number of past flown morphing capable aircraft examples have nonetheless emerged (Barbarino, Bilgen, Ajaj, Friswell, \& Inman, 2011; McGowan, Vicroy, Busan, \& Hahn, 2009; Min, Kien, \& Richard, 2010; Weisshaar, 2006). Variable sweep has arguably seen the most success, as it allows for significant performance changes and flight envelope extension for reasonable system specifications and 
spatial requirements, with a number of military examples. In the field of dihedral folding wingtips of interest here, the most notable past flown example lies in the XB-70 Valkyrie, a large supersonic strategic bomber developed in the 1970's, pictured in Figure 3. Note that the term folding is used here, as the relative simplicity of the hinged control surface movement and control, however large, could arguably qualify as a morphing system (Barbarino et al., 2011; McGowan et al., 2009).

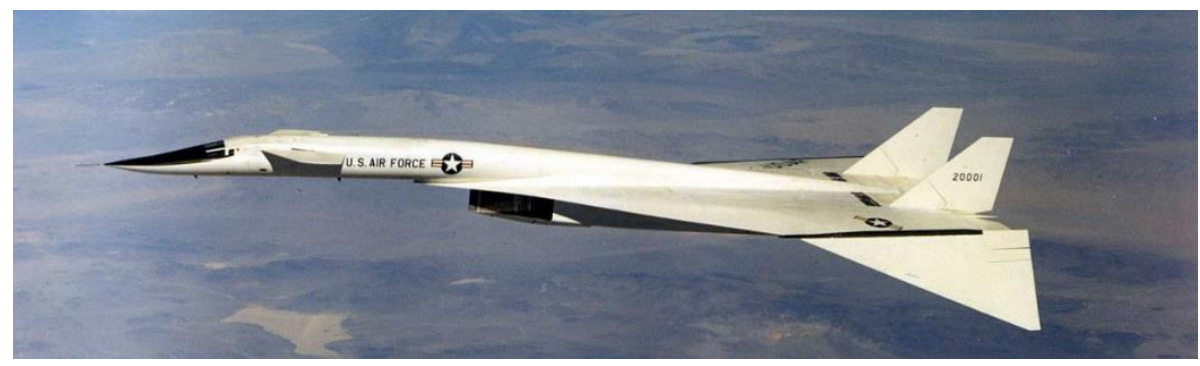

Figure 3. The XB-70 AV-1 in flight, with wingtips folded $25^{\circ}$ downward at low supersonic speeds.

Morphing aircraft research in the academic and industrial worlds are currently exploring a number of innovative and complex solutions in an effort to reduce weight and increase the performances of morphing devices. Some rely on compliance structures (Ajaj, Beaverstock, \& Friswell, 2015; Ajaj, Flores, \& Friswell, 2013; Campanile, 2005; Previtali, 2015) to replace heavy and bulky hinges. Conventional control actuators are also replaced by more power dense actuators such as Shape Memory Alloys (SMA) or Polymers (SMP) (Hartl \& Lagoudas, 2007). The morphing capability also includes smart skins (Thill, Etches, Bond, Potter, \& Weaver, 2008) to ensure aerodynamic shape continuity throughout the aircraft morphing spectrum has also received significant interest. Mathematical investigations for complete mission analysis and flight controls were also made (Bowman et al., 2007; Seigler, 2005; Seigler, Bae, \& Inman, 2004; Seigler, Neal, Bae, \& Inman, 2007) to highlight the benefits of multimission continuous morphing vehicles through simulation, but a number of daunting tasks remains to be tackled, specifically in actuation, systems and structural requirements. In the recent years, a wide variety of working examples have been set forward, using a combination of all or part of the above. This includes a multi-mission Z-fold aircraft concept model and wind-tunnel demonstrator (Bye \& McClure, 2007) or a mission adaptive compliant flap from development to setup and testing (Kota et al., 2006). Bourdin, Gatto, and Friswell (2008) developed an experimental wind tunnel model for aircraft control using folding wingtips with a more conventional actuation approach, highlighting their potential for longitudinal control when used in tandem. A corrugated skin concept for similar actuated wingtips was also investigated (Ursache, Melin, Isikveren, \& Friswell, 2008). A demonstrator of a combination of a new actuation and smart skin was also made for a wing profile camber morphing (Peel, Mejia, Narvaez, Thompson, \& Lingala, 2009). Lastly, a sub- 
scaled demonstrator was flown recently as part of the Spanwise Adaptive Wing (SAW) project (Kamlet \& Gibbs, 2018; Warwick, 2018). The NASA led tests highlighted the potential for subsonic commercial applications of in-flight dihedral wingtip morphing using SMAs, including increased fuel-efficiency, controllability and possibility to reduce tail size as deflected wingtips offered enhanced directional stability. Furthermore, the results on applications to the F18 wing are encouraging for the field of morphing aircraft using SMA (NASA Glenn Research Center, 2018).

\section{Application to Large Civil Aircraft}

In the last few years, a joint academic and industrial research project between Cranfield University, the University of Bristol and Airbus Group looked at evaluating potential benefits and feasibility of implementing in-flight dihedral folding wingtips on large civil aircraft, rather than simple ground fold devices. Mathematical models of a flared folding wingtip device fitted on a large civil aircraft have led to the assessment of the gust load alleviation capabilities (Castrichini et al., 2016) and impact on roll dynamics of the aircraft (Dussart et al., 2018). Wind tunnel tests also highlighted the loads alleviation potential of the wingtip on a sub-scale model (Cheung, Castrichini, \& Cooper, 2017; Cheung, Rezgui, Cooper, \& Wilson, 2018/2019). A summary of the findings around the use of folding hinged wingtips (Wilson et al., 2017) was also published as part of the same project. These past investigations have provided a wide spectrum of encouraging results for in-flight wingtip folding applications on large civil aircraft.

Concerns regarding the scalability to large civil aircraft flight of the technologies mentioned previously, particularly compliance structures, SMAs and SMPs were raised due to the dependency on weight, size and frequency of morphing required, maintenance and complexity. It remained unclear whether it would be plausible to rely on conventional actuation strategies (hydraulic or electric) for short term applications given the spatial and performance requirements, or if further development in actuation and morphing technologies were required to design feasible systems. This lack of certainty on full-scale actuation options for an in-flight folding wingtip device, a key system design criteria, motivated a review and analysis of the in-flight folding wingtip system capabilities used on the XB-70, undertaken to help further key development decisions in system design.

\section{Historic and Technical Development of the XB-70}

When investigating past developments in the field of in-flight morphing, one would be hard pressed not to find mentions of the iconic XB-70 Valkyrie pictured in Figure 4, Figure 5, and Figure 6 (Pace, 1990). The aircraft, which first flew in 1964, 10 years after its inception by the United States Air Force (Jenkins \& Landis, 2002; Pace, 1990) was designed as a strategic supersonic bomber for the Strategic Air Command. The conception obviously constituted an incredible challenge as it was intended for high altitude flights at three times 
the speed of sound, and required ground-breaking developments in many aspects of aerospace vehicle design.

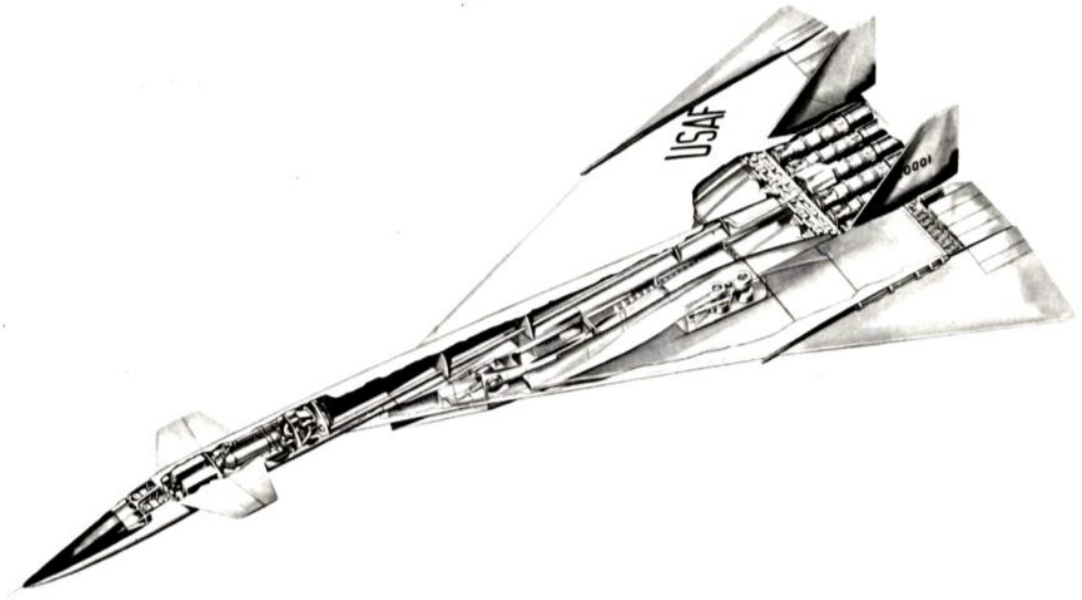

Figure 4. XB-70 cut through engineering drawing.

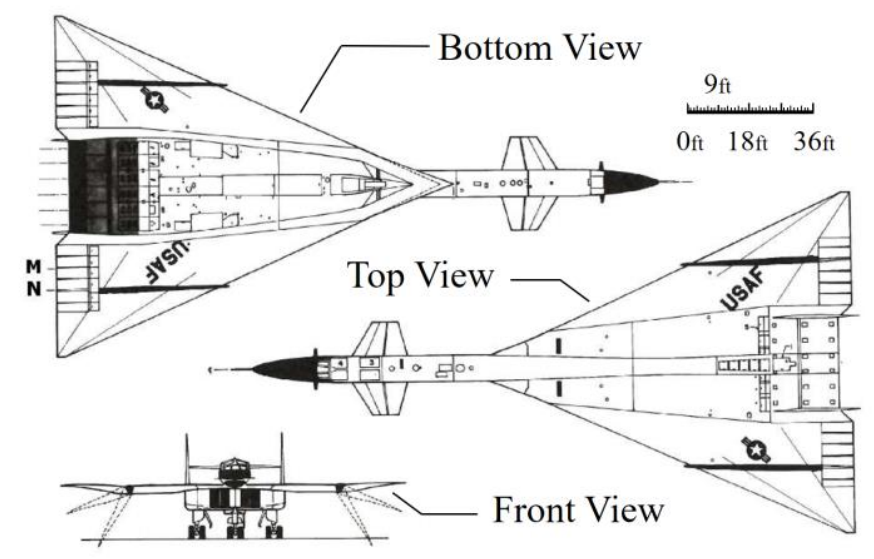

Figure 5. XB-70 geometric drawings.

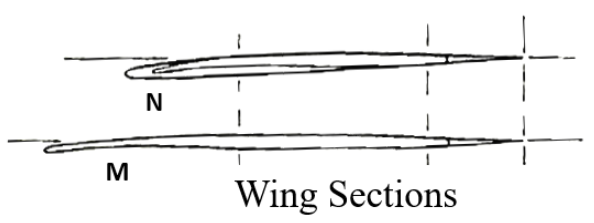

Figure 6. XB-70 wing profile sections, at both $\mathrm{M}$ and $\mathrm{N}$ truncation planes.

Clever aerodynamic engineering and the use of an unconventional (at the time) canard design feature allowed for adequate aerodynamic performances to be achieved throughout the flight envelope, from landing speeds to Mach 3 . A hinged nose cone was also used, which, when lowered, would give the pilots 
sufficient visibility during low altitude subsonic flights. At higher speeds, the upper panel of the nose cone would then realign with the fuselage to restore better aerodynamic performances, a feature latter used on the Concorde. An obvious visual and aerodynamic design feature was the large cantilevered delta wing, which included in-flight folding wingtips. The XB-70 was designed to use compression lift, a phenomenon also referred to as Mach wave riding, which was demonstrated with the help of wind-tunnel tests (Pace, 1990; Ross \& Rogerson, 1983). It was shown to provide an increase in total lift at supersonic speeds as wingtips folded downward, and would capture the shock waves generated by the aircraft. Wing lift could therefore significantly increase by up to $30 \%$ without any drag penalty (Jenkins \& Landis, 2002; Ross \& Rogerson, 1983), which arguably gave the design presented by North American the edge over the competing Boeing concept at the end of the second and final competitive design phase. Note that following a congressional inquiry demanded by Boeing, it appeared that compression lift and related performance improvements ultimately convinced the Air Force to use a design that Boeing deliberately neglected by lack of faith in the concept and preliminary results (Jenkins \& Landis, 2002). It was also demonstrated that the folding wingtips also enhanced the directional stability of the vehicle, even though it was still poor for the first vehicle variant. A wing dihedral modification by $5^{\circ}$ on the next demonstrator (AV-2) led to better performances. The folding wingtips also allowed for a significant reduction in fin area. If the wingtips had been fixed, then the vertical fins required for stability would have needed to be double in area to those used in the folding capable design. Hence, this greatly reduced parasitic drag due to the vertical stabilisers and overall structural weight of the airframe. Furthermore, it also helped move the centre of lift closer to the centre of gravity at supersonic speeds, reducing the need for trim corrections. As wingtips folded, the effective wing area near the trailing edge (due to the drooping of the profile on the wingtip) was reduced, therefore decreasing the total lift aft of the centre of gravity and the needs for trim corrections, consequently leading to improved aerodynamic efficiency. For these reasons, the overall performance benefits greatly justified the use of folding wingtips on the XB-70 despite additional mass and system complexity.

A number of significant breakthroughs were also made in many other fields, such as propulsion, engine design, materials and fuel. These advances were necessary to ensure that the aircraft was capable of sustained supersonic high-altitude flights and cope with the thermal and structural implications on both airframe and systems. For instance, a new honeycomb skin was developed to provide the required airframe weight reduction whilst maintaining stiffness of the overall structure. Thermal expansion and overall heating of the airframe, a phenomenon later encountered on the Concorde as well, also led to significant changes to internal systems and even livery application methods and paint composition.

However, the XB-70 program never took-off to reach its original potential. Even before the tragic loss of the second XB-70 aircraft along with 
one of the pilots on-board (Davies, 2018; Jenkins \& Landis, 2002; Pace, 1990). Since the early days of development, the program was crippled by political and economic conflicts. Moreover, significant advancements in Inter Continental Ballistic Missiles (ICBM) and Ground-Air Missiles threatened the very purpose of the plane. Before the first test-flight, the program had already lost significant political momentum and funding, with the Air Force reducing the fleet to two demonstrators and a third example, already under construction, cancelled. The project was henceforth intended for large supersonic aircraft flight research, and paved the way for the development of Super Sonic Transport (SST) such as the Concorde, but was a mere shadow of the original vehicle imagined and designed for the Strategic Air Command.

Truly captivating stories of the XB-70 project, both from an historical and political point of view, as well more specific aircraft design details can be found in excellent literature pieces (Jenkins \& Landis, 2002; Pace, 1990). As this particular paper focuses on the folding wingtip system, the rest of the discussion will henceforth focus on the folding wingtip devices fitted on the experimental plane.

\section{System Requirements for Supersonic Actuation}

One must admit that details regarding the development and characteristics of the folding wingtip actuation devices is very scarce. Most of the existing available literature focuses on the innovations which were made in the fields of aerospace materials, fuel management and engine design required by supersonic flight of such a large vehicle. Arguably, these aspects drew significantly more attention and concerns compared to the wingtip folding mechanism problem. The authors believe that, with so many other challenges and problems occurring throughout the program (Jenkins \& Landis, 2002; Pace, 1990), the folding wingtip device was not judged as significant to the XB-70 historical contribution.

\section{Folding Hinge Actuator and Wingtip Details}

However, enough information can be gathered to understand and reasonably estimate the capabilities of the folding hinge mechanism. Relevant geometric details regarding wingtip size and aerofoil thickness are summarised in Table 1, which gathers data obtained from various geometric drawings (Jenkins \& Landis, 2002; Pace, 1990) and data packs (Jenkins, DeAngelis, Friend, \& Monaghan, 1969). The complete hinge mechanism is sketched in Figure 7. XB-70 actuator shaft layout Figure 7, extracted from XB-70 general arrangement document, and where the central shaft which served as an input to six power hinges distributed along the fold line is clearly shown. Another sketch given in Figure 8 show each power hinge was linked to the structure of the wing. A couple of Vickers hydraulic motors situated within the fuselage were used to pressurise the hydraulics system linked to each wingtip. For redundancy purposes, only one pump was used in the main hydraulic network whilst the second would have been used as back-up in the event of a hydraulic pressure 
failure. Hence a total of 4 pumps on the aircraft dedicated solely to the wingtip mechanisms (Pace, 1990). The entire wingtip actuation motor and set of power hinges were housed within a black magnesium thorium fairing which covered the entire wingtip hinge line, from wing leading edge to elevon root, as shown in the above Figure 4. Obviously, this entire set of power hinges came with a significant size and mass cost to the aircraft.

Table 1

Geometric details of the XB-70 wingtip

\begin{tabular}{lrc}
\hline Folding Wingtip (Single Tip) & & \\
\hline Area & 48.4 & $\left(\mathrm{~m}^{2}\right)$ \\
Span & 6.3 & $(\mathrm{~m})$ \\
Aspect ratio & 0.83 & \\
Taper Ratio & 0.05 & \\
Root Chord (9.67m spanwise) & 14.6 & $(\mathrm{~m})$ \\
Tip Chord (16m spanwise) & 0.7 & $(\mathrm{~m})$ \\
Mean aerodynamic chord & 9.8 & $(\mathrm{~m})$ \\
Down Fold Angles & {$[0,25,65]$} & $\left({ }^{\circ}\right)$ \\
Aerofoil Thickness (\% at root) & 2.5 & $(\%)$ \\
\hline
\end{tabular}

A close-up picture of a Curtiss-Wright power hinge is given in Figure 10 for a similar geometry to those which would have been used on the Valkyrie. Exact size and mass of each power hinge remains unclear, other than advised estimates made as follows. A picture taken during vehicle assembly puts the gearbox mechanism in perspective to an operator, as shown in Figure 9. Aerodynamic profile thickness at the fold line was estimated at best to be $36 \mathrm{~cm}$ using data from Table 1 . The power hinge appears to be roughly the diameter of an adult forearm, and fits within the dimensions of the aircraft structural wing box. Depth of the device can also be assumed to be similar. Thus, the power hinge is comparable to a cube-like shape with a side of roughly $30 \mathrm{~cm}$. Made primarily of H-11 steel (Ross \& Rogerson, 1983) with a room temperature density of $7.80 \mathrm{~g} . \mathrm{cm}^{-3}$, the weight is therefore estimated to lie between $120 \mathrm{~kg}$ and $160 \mathrm{~kg}$ assuming a gearbox density ratio between $35 \%$ to $45 \%$, standard in these devices. More precise predictions using an in-house tool estimated the mass of the power hinge at around $140 \pm 10 \mathrm{~kg}$, with a safety margin depending on attachments thickness, shaft sizes and other parameters, narrowing previous estimates. 


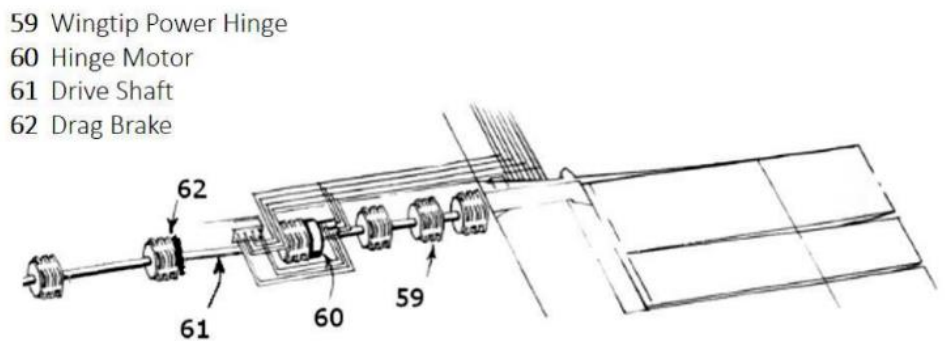

Figure 7. XB-70 actuator shaft layout.

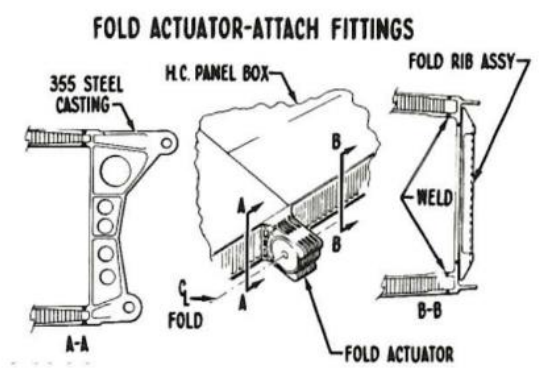

Figure 8. XB-70 actuator structural implementation.

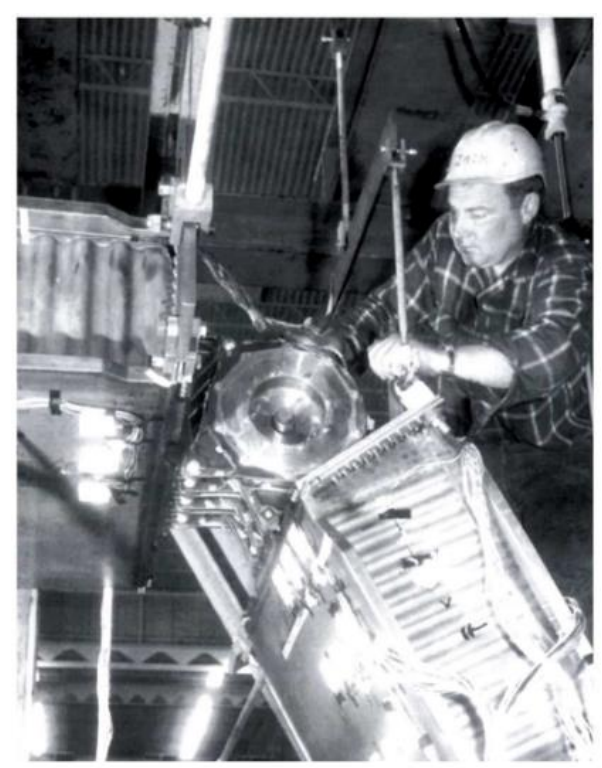

Figure 9. XB-70 power hinge inside the wingbox, with operator for size comparison. 


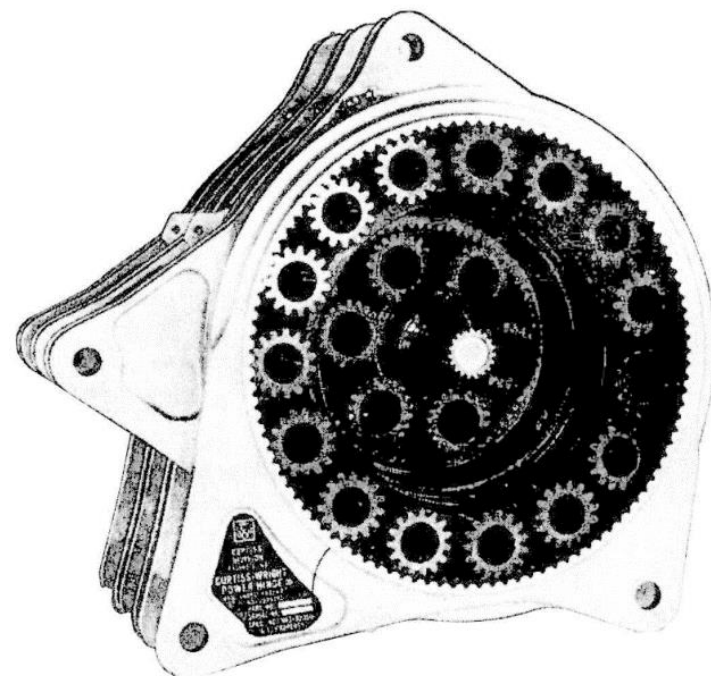

Figure 10. A Curtiss-Wright power hinge similar to those found on the XB-70.

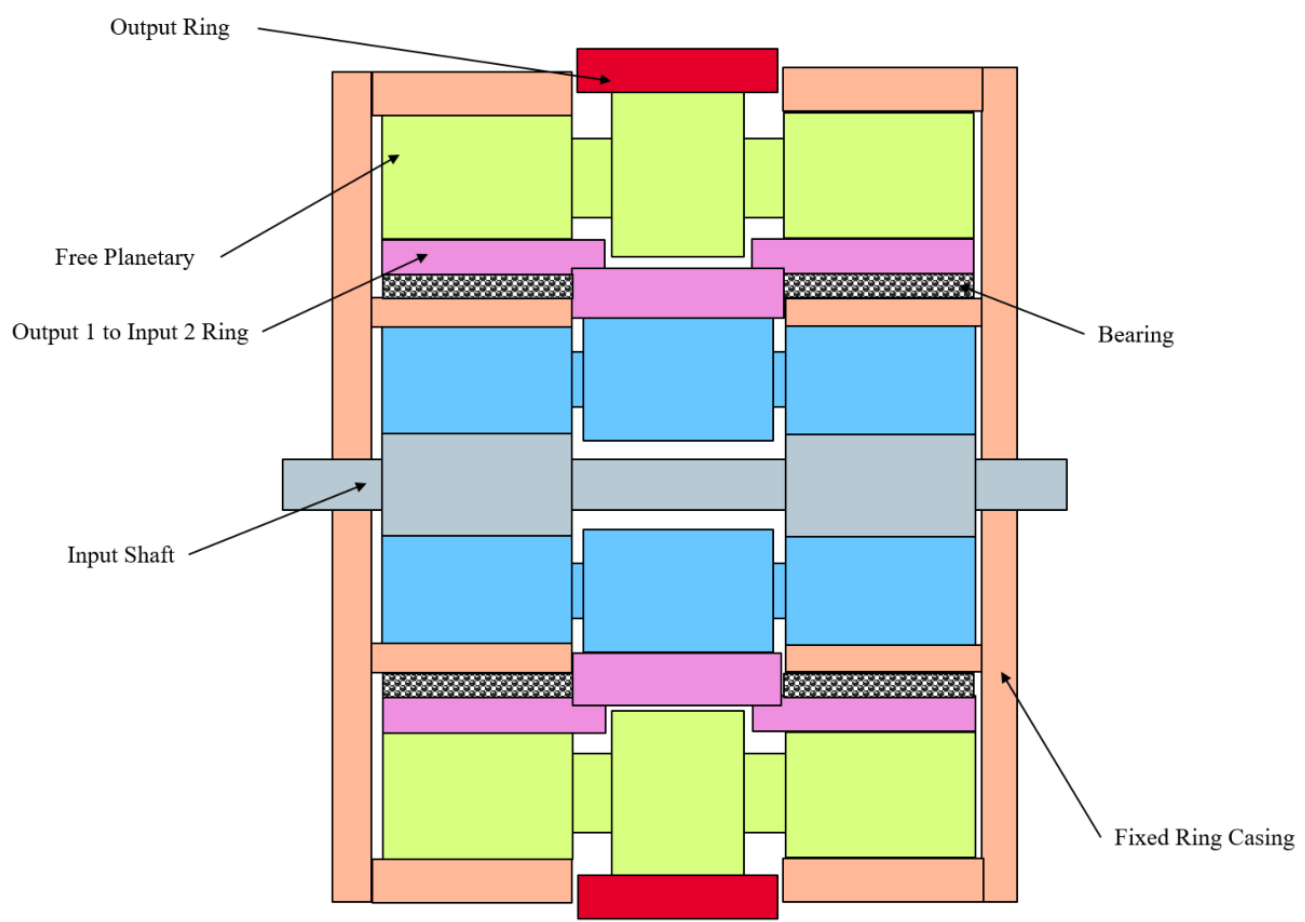

Figure 11. Cut schematics of a two level - two stages planetary gear power hinge. 
Accurately counting number of teeth and estimating size for retroengineering purposes is nearly impossible. Nonetheless, the unreferenced industrial report from which Figure 10 was extracted mentions a reduction ratio of 2440-to-1, with two stages driven by a common sun gear, giving high torque in a small diameter. Two concentric stages of reduction are used, such that the output ring gear of stage one serves as an input to the second stage as shown in Figure 11.The power hinge used for the XB-70 was similar in design and reportedly capable of an outstanding $32,000-t o-1$ ratio $\left(R_{G}=32000\right)$. It is unclear however through which combination exactly such ratios were achieved as diameters and teeth numbers as well as the arrangement of fixed and moving gears have not been found. Note that this ratio is very high compared to conventional and heavier planetary gear systems.

With six devices per wingtip, the total gearbox mass per wingtip can be estimated at $840 \mathrm{~kg}$, solely for the power hinges. This weight penalty then enabled the reduction of vertical fin by approximately half of its area though little to no data is available on the structural changes to the wing required for incorporation of the hinge set.

\section{Estimating Fin Mass Savings}

To put the weight of the hinges into perspective, it must be compared to the aircraft fin and overall masses. The XB-70 had an Maximum Operating Weight (MOW) of $m_{M O W}=242500 \mathrm{~kg}$, Maximum Take Off Weight (MTOW) of $m_{\text {MTOW }}=246000 \mathrm{~kg}$, and Operating Empty Weight $(\mathrm{OEW})$ of $m_{O E W}=$ $115030 \mathrm{~kg}$. For commercial airliners, a rough estimate of the vertical tail weight can be obtained by assuming it equal to $1 \%$ of the $m_{O E W}$. However, as the XB-70 is neither a commercial airliner, nor of conventional configuration, it was suitable to use the ratio of vertical fin weight over area to compute the total mass of the aircraft fins.

Typical ratios, or surface densities, were computed for various commercial aircraft. Obviously, internal structures required to cope with aerodynamic stresses, materials used and to some extent profile type and thickness all contribute to differences in total fin mass between a commercial aircraft and the extensively different XB-70. However, this assumption should be sufficient to derive estimates of comparable accuracy to that of the hinge weight. For a fin area $A_{f}=21.7 \mathrm{~m}^{2}$, a surface density $\sigma_{f}=22.5 \mathrm{~kg} . \mathrm{m}^{-2}$ similar to that of commercial aircraft with comparable fin sizes was assumed as shown in Figure 12. This particular surface density is lower than that of comparable $m_{O E W}$ commercial aircraft at $27 \mathrm{~kg} . \mathrm{m}^{-2}$. In the latter, the single fin configuration requires a larger area per fin, hence height and therefore internal structural weight to cope with the aerodynamic stresses. By having two smaller fins, the XB-70 can use a smaller surface density, effectively reducing weight for a given vertical fin area. With $A_{f}$ and $\sigma_{f}$ in hand, the mass of a single fin is compared against $m_{O E W}$ as shown in Figure 13. Single fin mass for the XB-70 was assessed at approximately $m_{f 1}=500 \mathrm{~kg}$ or $0.45 \%$ of $m_{O E W}$. Total mass 
of the fin set is therefore estimated at $m_{f 2}=2 \times m_{f 1}=1000 \mathrm{~kg}$, or $0.9 \%$ of $m_{O E W}$.

It was claimed in the literature that folding wingtips helped divide fin size in half by enhancing directional stability when deployed. Considering a non-wingtip folding aircraft, with a single fin area of $A_{f}=43.6 \mathrm{~m}^{2}$ required for equivalent directional stability, surface density would have been set to $\sigma_{f}=$ $27 \mathrm{~kg} \cdot \mathrm{m}^{-2}$, as shown in Figure 13 In turn, this would have led to a single fin weighing nearly $m_{f 1}=1170 \mathrm{~kg}$, or slightly over $1 \%$ of $m_{O E W}$. As the XB-70 uses a dual fin configuration, that leads to fins weighing at $m_{f 2}=2 \times m_{f 1}=$ $2340 \mathrm{~kg}$ or $2 \%$ of $m_{\text {OEW }}$.

Overall, the folding wingtip system, with the two sets of power hinges alone, weighing approximately $1680 \mathrm{~kg}$, has helped save an estimated $1340 \mathrm{~kg}$, or nearly $60 \%$ in vertical tail mass, whilst enhancing directional stability at supersonic speeds. Note that other systems, including the hydraulics, electric systems, shaft, and brakes were not accounted for in this trade-off. Nonetheless, it was shown that lift performance increase due to compression lift and the forward shift in the aircraft centre of lift at supersonic speeds has clearly made the system relevant, and even essential, for the XB-70 to reach required performance and control.

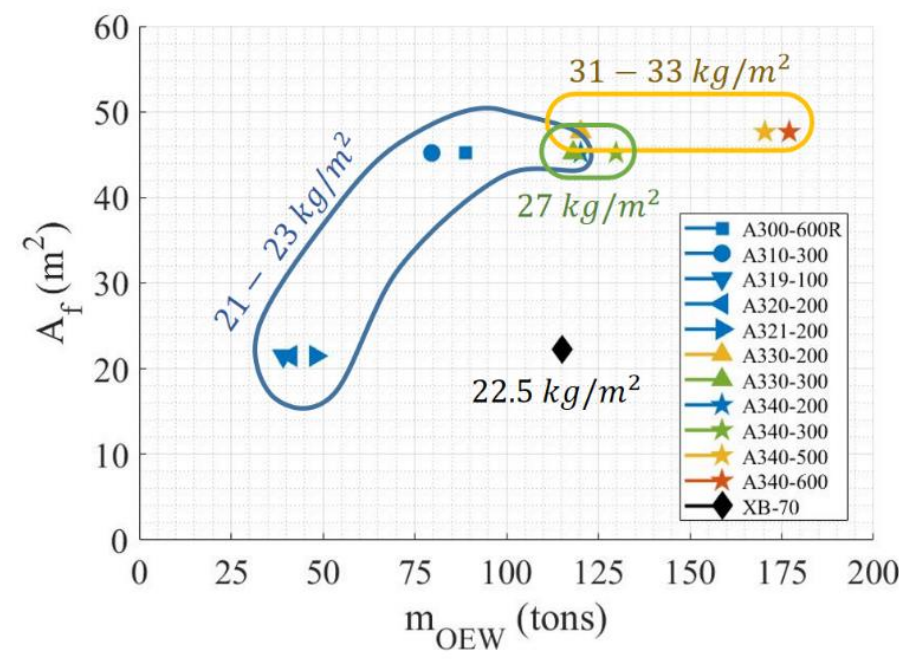

Figure 12. Fin surface density $\sigma_{f}$ as a function of fin area $A_{f}$ and $m_{O E W}$. 


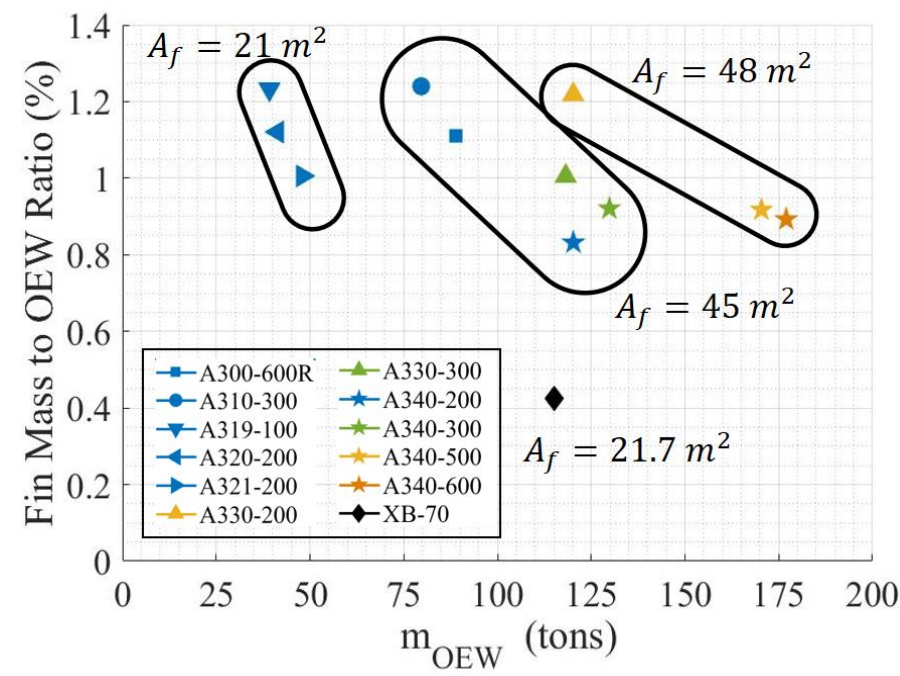

Figure 13. Fin mass $m_{f}$ to $m_{O E W}$ ratio as a function of fin area $A_{f}$ and $m_{O E W}$.

The reader should note that such a drastic fin area reduction was achieved for the following reasons. Firstly, folding wingtips were deflected to very high dihedral angles (up to $65^{\circ}$ ) and effectively served as additional fins. Secondly, the delta wing configuration placed the folding tips near the tail of the aircraft, or nearly aligned with the vertical fins of the vehicle. This in turn, allowed for much more authority around the vertical axis given the forward position of the centre of lift and centre of gravity. In comparison, if such a device was to be used in a conventional aircraft configuration, the wingtip position along the longitudinal axis would not be as far aft, greatly reducing the authority of the wingtips, now similar to additional fins. Nonetheless, if weight savings could be achieved by reducing vertical tail size (even to less drastic extents), it would still greatly help in the case for in-flight folding wingtip device implementation.

\section{Power Hinge Capabilities Assessment}

Following the estimation of actuator size and mass, interest shifts to the torque or loading capability of the device. The necessity to use six power hinges was dictated by aerodynamic twist and bend loads experiences throughout the flight envelope. It is unclear whether the actuators were designed to deal with a single mechanical component failure, with the lack of redundancy in the mechanical link suggesting this was acceptable on an experimental military aircraft. For simplification, it is assumed that each of the power hinges was designed to cope with a sixth of the maximum allowable hinge moment, without safety margins. This should give a fairly conservative estimate of the maximum allowable hinge moment or torque per actuator. 
The nominal folding strategy of the XB-70 wingtips, illustrated in Figure 14 and Figure 15 was therefore investigated. From these graphs, it is clear that wingtips were to be held planar until higher transonic speeds. At Mach 0.9 the wingtips were folded to a $25^{\circ}$ downward angle. This anhedral fold was increased when reaching Mach 1.4 to a $65^{\circ}$ deflection and maintained throughout the higher end of the velocity spectrum. Valuable in-flight data and measurements obtained using strain gauges to measure the hinge moments at multiple flight conditions were extracted from a NASA report (J. M. Jenkins et al., 1969). Approximations of the folding wingtip hinge moment coefficients made in the report are redrawn in Figure 16. These coefficients correspond to an entire set or wingtip device (a combination of all six power hinges and motor). The coefficients can then be scaled back to the equivalent hinge moment acting on the device as shown in Figure 17.

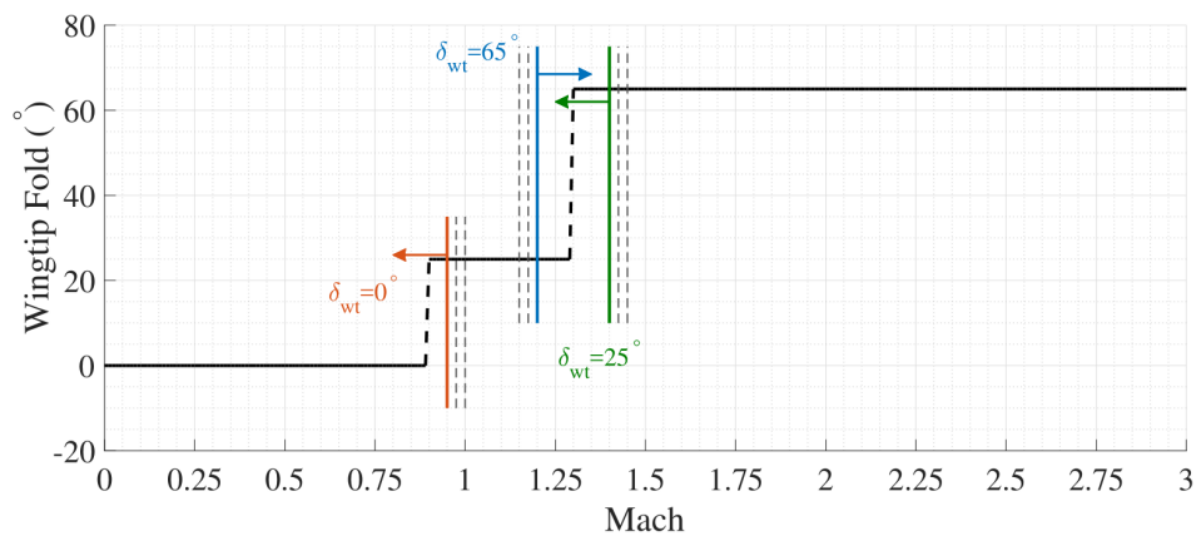

Figure 14. XB-70 nominal folding strategy against airspeed.

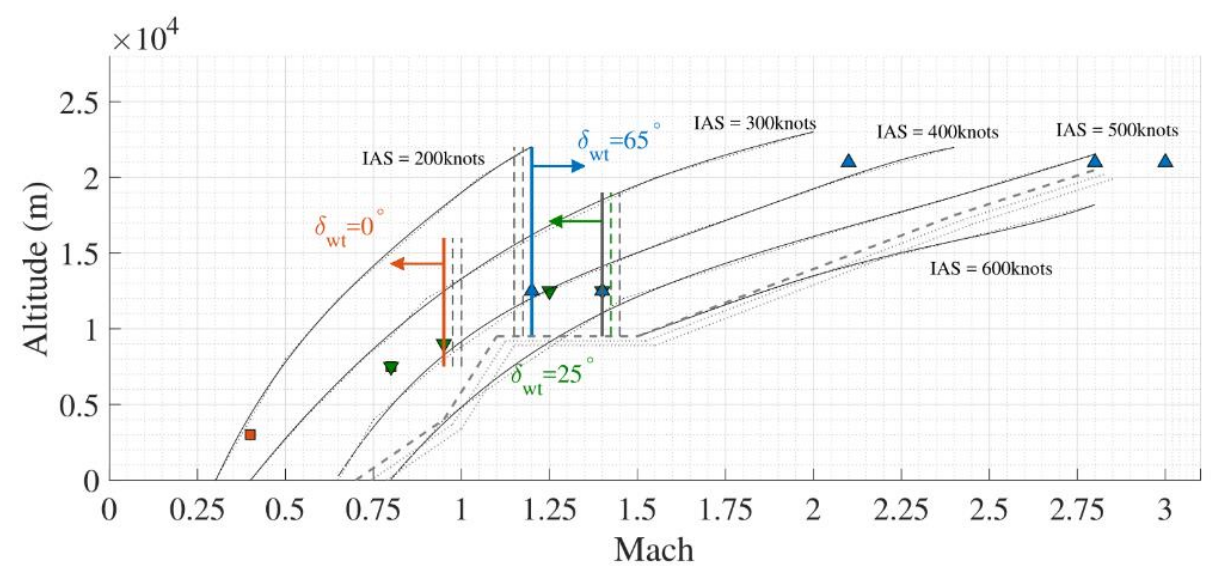

Figure 15. XB-70 typical flight envelope, with folding limitations and flight conditions. 
The scaling to hinge moment is done using the following formula, similar to the equation conventionally used for ailerons, elevators or rudders, also found in the original NASA document (J. M. Jenkins et al., 1969):

$$
\begin{aligned}
C_{h_{w t}} & =\frac{H_{w t}}{\bar{q} \times S_{e} \times l_{w t}} \\
\Leftrightarrow \quad H_{w t} & =C_{h_{w t} \times \bar{q} \times S_{e} \times l_{w t}}
\end{aligned}
$$

where $C_{h_{w t}}$ is the hinge moment coefficient acting around the fold line (bending), $\bar{q}$ is dynamic pressure, $S_{e}$ is the wingtip surface area and $l_{w t}$ is the wingtip length $C_{h_{w t}}$ and dynamic pressure $\bar{q}$ are both functions of the flight conditions at which the measurements were made, the details of which are provided in Jenkins et al. (1969). Dynamic pressures used in this study were derived using the compressibility corrections and atmospheric temperature models adequate for high altitude supersonic flight conditions. Note that the dynamic pressures computed are comparable but not strictly identical to those given in the NASA report (Jenkins et al., 1969).

With dynamic pressure $\bar{q}$ and hinge moment coefficients $C_{h_{w t}}$ in hand, it was possible to derive the hinge moment $H_{w t}$. Both are illustrated in Figure 16 and as a function of flight conditions at which they were measured. The general trend shows an increase in bending moment with angle of attack as expected: the lift produced on the lifting surface increases as the aircraft pitches up relative to the flow. Somewhat counter intuitively, the maximum hinge moments are not obtained at the higher Mach number. This is due to: a) air density reduces at higher altitudes, and therefore counter acts the effect of increasing airspeed, and b) as the wingtips are folded downwards, the profile shape and pitch trimmed attitude changes induces an overall reduction in lift on the wingtips (Jenkins \& Landis, 2002; Pace, 1990).

Table 2

Flight Conditions Used for Hinge Moment Measurements on the XB-70

Folding Wingtip Device

\begin{tabular}{rrrrr}
\hline \multicolumn{5}{c}{ Flight conditions for hinge moment coefficient assessment } \\
FC & Mach & Alt. $(\mathrm{m})$ & Fold $\delta_{w t}\left(^{\circ}\right)$ & $\bar{q}\left({ }^{\circ} . m^{-2}\right)$ \\
\hline 1.1 & 0.4 & 3000 & 0 & 7850 \\
1.2 & 0.8 & 7620 & 0 & 16841 \\
2.1 & 0.8 & 7620 & 25 & 16841 \\
2.2 & 0.95 & 9144 & 25 & 19005 \\
2.3 & 1.2 & 12190 & 25 & 20379 \\
2.4 & 1.4 & 12190 & 25 & 27738 \\
3.1 & 1.25 & 12190 & 65 & 22113 \\
3.2 & 1.4 & 12190 & 65 & 27738 \\
3.3 & 2.1 & 15000 & 65 & 45991 \\
3.4 & 2.8 & 21340 & 65 & 26990 \\
3.5 & 3 & 21340 & 65 & 30984 \\
\hline
\end{tabular}




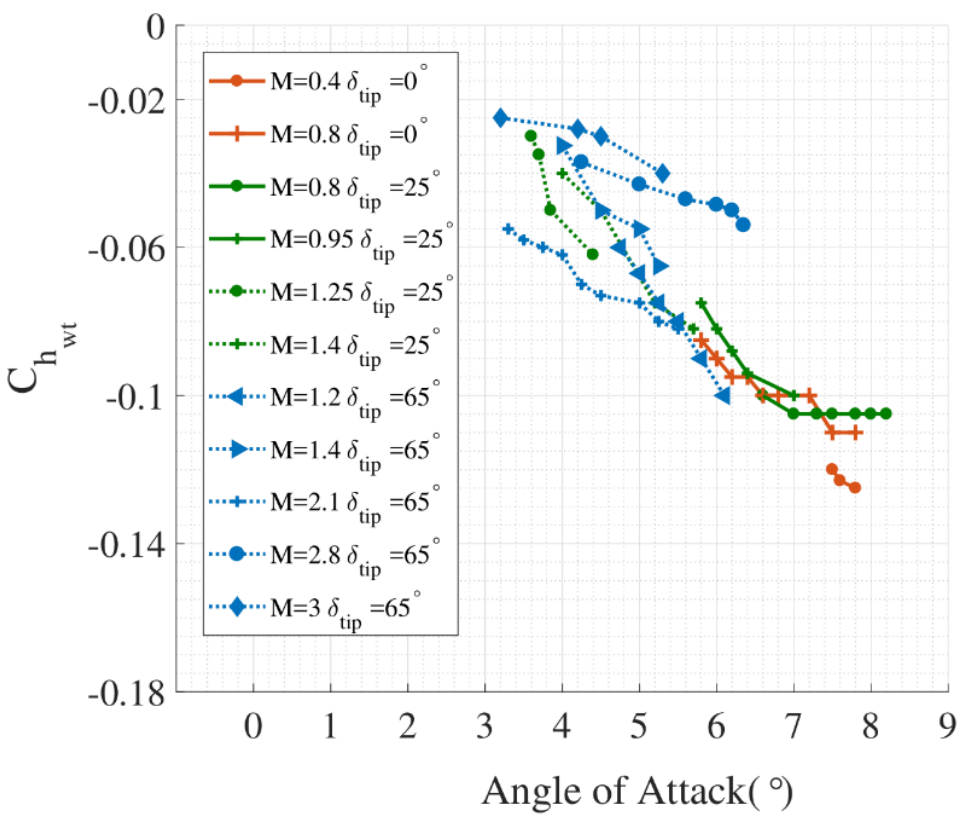

Figure 16. Hinge moment coefficient $C_{h_{w t}}$ against angle of attack.

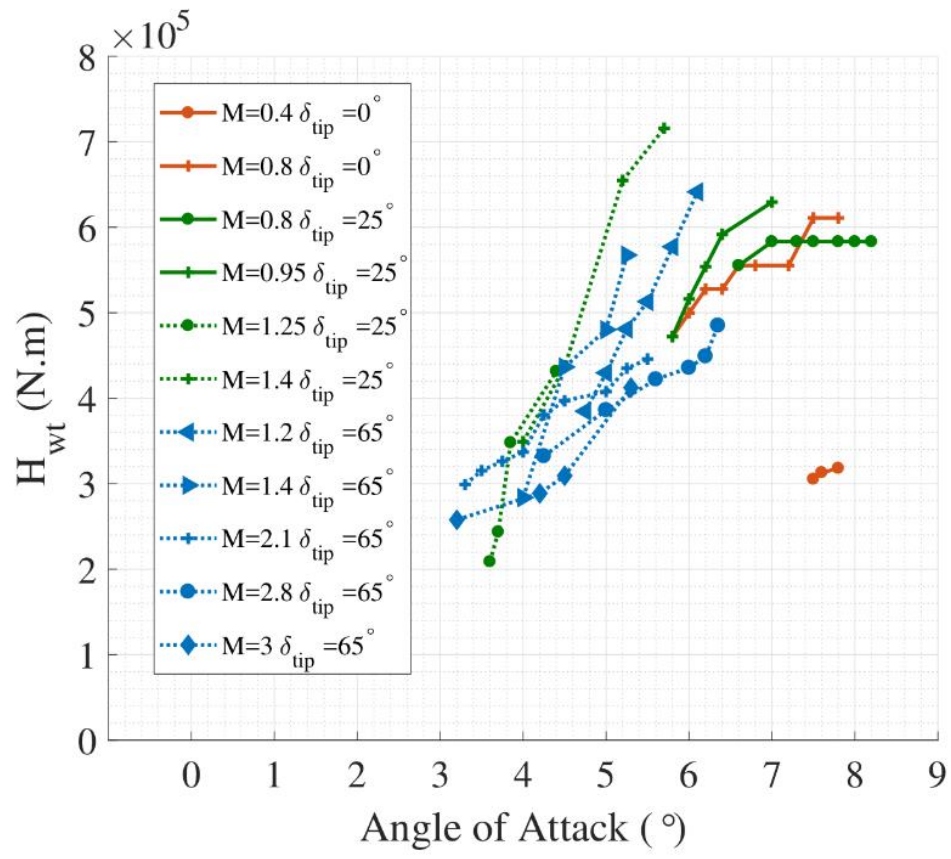

Figure 17. Hinge moment $H_{w t}$ against angle of attack.

Derived from both trimmed steady flight and coordinated turns (Jenkins et al., 1969) these results are reliable indicators of the power hinge capacity to withstand aerodynamic loads and fold the wingtips in flight. In fact, the highest 
bending moments $M_{x}$, reaching up to $700 \mathrm{kN}$.m were obtained in the lower supersonic regions with a $25^{\circ}$ deflection. In the subsonic region, the hinge moment lays within $450 \mathrm{kN} . \mathrm{m}$ and $600 \mathrm{kN}$.m, with very little difference between the baseline and $25^{\circ}$ deflection cases. As a single motor was used, the gear ratio $R_{G}=32000$ suggests that, in the case of an idealised system (no friction), a maximum torque $T_{\text {shaft }}^{\max }=22 \mathrm{~N} . \mathrm{m}\left(M_{x}^{\max } / R_{G}\right)$ would have been required to drive the shaft feeding through all power hinges. In reality, this would have been significantly more, due to friction and efficiency of the hinges. But comparable torques are easily achievable using electric or hydraulic rotary motors with diameters well below $30 \mathrm{~cm}$, thus falling within acceptable ranges. These results clearly show that the wingtip folding devices were capable of coping with high bending moments. Furthermore, none of the tests included wingtip fuel tanks, for which the system was designed originally.

Another point of interest is wingtip shaft rotational speed $\mathrm{rpm}_{\text {shaft }}$ during wingtip folding. With the reduction ratio $R_{G}$ of the power hinges, and data extracted from non accelerated footage of in-flight folding of the wingtips, it is possible to get an estimate of the shaft rotational speed in revolutions per minute. A video sample was used to measure both time to fold from ideal $0^{\circ}$ to $25^{\circ}, t_{0^{\circ}-25^{\circ}}$ and change in fold angle during that time $\Delta \delta_{w t} . r p m_{\text {shaft }}$ is calculated using:

$$
r p m_{\text {shaft }}=\mathrm{R}_{\mathrm{G}} \times \frac{\Delta \delta_{w t} \times 60}{t_{0^{\circ}-25^{\circ}} \times 360}
$$

where $t_{0^{\circ}-25^{\circ}}$ was estimated at $17 \pm 0.5 s$ and $\Delta \delta_{w t}$ was assumed ideal at $25^{\circ}$. A minimum $\Delta \delta_{w t}=20^{\circ}$ was also considered. These parameters led to an approximated $\mathrm{rpm}_{\text {shaft }}=8000 \mathrm{rpm}$ (maximum of $8100 \mathrm{rpm}$ and as low as $6100 \mathrm{rpm}$ in the worst measurement case at $t_{0^{\circ}-25^{\circ}}=17.5 \mathrm{~s}, \Delta \delta_{w t}=20^{\circ}$ ). This value sits well within the range of realistic motor capabilities that could be fitted within the wing.

Overall, the size, mass and actuation power of the folding mechanism fitted on the XB-70 were presented in this section. It is now clear that powerful in-flight wingtip actuators have been used in the past for military applications, and could potentially serve as inspiration to future civil concepts. The following step is naturally to compare these results against a number of wing box sizes and assess if such a device could be applied to large civil aircraft.

\section{Inspiration for a Large Civil Aircraft Design}

In this section, the idea of using a similar system to that of the XB-70 in a number of use-case aircraft will be tackled. In fact, a span extended single aisle aircraft wing concept was used as a baseline and scaled to various sizes. The spanwise position of the wingtip hinge was kept constant and consistent with ground operational limitations. Hence the challenge is to fit a sufficient number of power hinges within a thinner aerofoil profile and shorter chord 
length than those of the XB-70. Aerodynamic loads should also differ substantially from that of the experimental plane, as flight conditions and wingtip area are drastically different.

\section{Design Space Calculations}

Different wing variants lead to a variety of aerodynamic profile thickness, chord, and aerodynamic loading in cruise. The aerodynamic and structural properties of an aircraft wing were therefore implemented within a geometrical initialisation environment derived from $\mathrm{CA}^{2} \mathrm{LM}$, an aeroservoelastic framework developed at Cranfield University (Andrews, 2011; Dussart, Portapas, Pontillo, \& Lone, 2018). An illustration of the wing once implemented is given in Figure 18. Furthermore, the baseline wing was modified in chord $\bar{c}$, thickness $t$ and span $s$ using a global scaling factor so that root chord $\overline{c_{r}}$, tip chord $\overline{c_{t}}$, span and profile thickness to chord ratio at the hinge line $t / \overline{c_{h}}$ vary. This multi-dimensional scaling of the wing, gives a sufficiently precise idea of available dimensions as a function of wing size despite being relatively unrealistic. Details of the wings investigated herein are given in Table 3 where the original baseline wing is given in bold. The hinge line central point (intersection with the centre chord position) was fixed at $17 \mathrm{~m}$ to respect ground limitations for all wings. A change in wingtip length $l_{w t}$ is therefore introduced. Profile sizing results with both line of flight $\overline{c_{h}}$ and maximum hinge thickness at the hinge line $t_{h}$ are also given.

Table 3

Geometric Details of the Wings Investigated

\begin{tabular}{rccccccrrr}
\hline \multicolumn{1}{c}{ Wing Characteristics at root, tip and hinge positions } \\
$\mathrm{N}^{\circ}$ & $S$ & $\overline{c_{r}}$ & $\bar{c}_{h}$ & $\bar{c}_{t}$ & $t_{h}$ & $t_{h} / \bar{c}_{h}$ & \multicolumn{2}{l}{$l_{w t}$} & \multicolumn{1}{c}{$M_{x}$} \\
& $(m)$ & $(m)$ & $(m)$ & $(m)$ & $(m)$ & $(\%)$ & $(m)$ & $(k N . m)$ \\
\hline 1 & 21.0 & 5.813 & 1.780 & .703 & .194 & 10.9 & 4 & - \\
$\mathbf{2}$ & $\mathbf{2 2 . 5}$ & $\mathbf{6 . 2 0 0}$ & $\mathbf{1 . 8 9 9}$ & $\mathbf{. 7 5 0}$ & $\mathbf{. 2 0 9}$ & $\mathbf{1 1 . 0}$ & $\mathbf{5 . 5}$ & $\mathbf{8 0}$ \\
3 & 24.0 & 6.643 & 2.035 & .804 & .230 & 11.2 & 7 & - \\
4 & 25.0 & 6.920 & 2.120 & .837 & .242 & 11.3 & 8 & 170 \\
5 & 26.0 & 7.200 & 2.205 & .871 & .253 & 11.4 & 9 & 200 \\
\hline
\end{tabular}

From these spatial sizing results, it is possible to have an appreciation of the size of the available profile compared to that of the XB-70. A visual comparison is made in Figure 19 where both XB-70 and baseline civil wing are shown. It is clear that, where six power hinges could easily be fitted within the XB-70 wing, it is widely different in the case of the civil aircraft wing, regardless of the variant. The profile is both too thin to fit a power hinge without using an aerodynamic fairing and too short to fit six along the hinge line. But it should not need to, as smaller wingtips and different flight conditions, hinge bending moments will surely lead to smaller wingtip actuation devices, as we will see in the following section. 


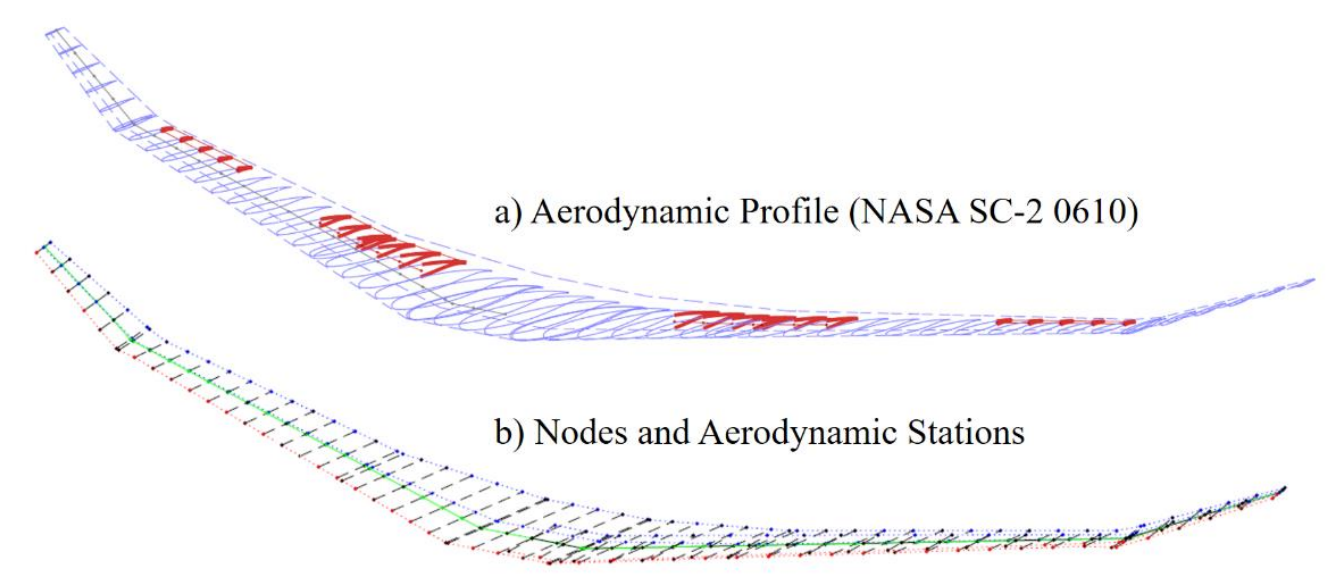

Figure 18. Wing layout after geometric implementation within the framework, with a folded wingtip at $17 \mathrm{~m}$, folded upward by $15^{\circ}$.

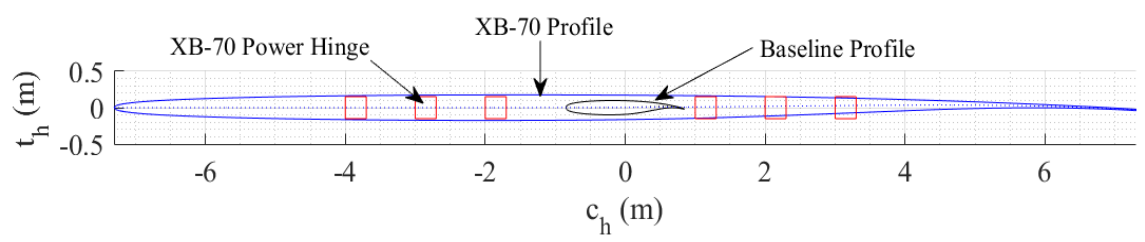

Figure 19. Profile size comparisons between XB-70 and wing of interest (NASA SC-2 0610 used for illustrative purposes).

\section{Loads Scalability to the Civil Aircraft Wing}

Prior investigations were made to identify the aerodynamic forces and moments acting on the hinge line at cruise, for different wing variants. These results are provided in Table 3 . Focusing solely on the hinge bending loads, it was found that a maximum of $200 \mathrm{kN}$.m would be reached in cruise conditions for the larger wing variant, whilst the baseline wing would only have to fight against $80 \mathrm{kN}$.m. This is well below the $\mathrm{XB}-70$ values derived in the previous sections and points to a possible reduction in the required number and ratio of the power hinges, effectively reducing the size of the entire actuation system. In fact, if similar hinges in reduction ratio were to be implemented, the system could do with just a pair of actuators on each wing. In their current state, an aerodynamic fairing would obviously be required, a daunting engineering task in itself. It is also possible to use multiple, yet smaller power hinges and motors to help with redundancy and sizing of the system, which could overall greatly improve the final solution and cut out the needs of an aerodynamic fairing, similar to flap track fairing positioned at the hinge line for instance. 
Overall, it was found that despite being significantly larger than the available space, the use of conventional hinged actuation for the folding wingtip concept is not as far-fetched in terms of dimensional sizing as previously assumed. It is possible to nuance the gap in size, especially knowing that performances of the final device fitted on the civil aircraft wing are closely linked to the final system size, due to the trade-off in torque and rotation speed in the power hinge. The sizing of actuator elements and transmission rods are outside the scope of this paper, but motor and shaft dimensions can be relatively well predicted using simple physics based techniques (Dussart, Lone, \& O'Rourke, 2019). Gearbox sizing with adequate teeth size for safe loads transmission is more tedious. However, a similar solution to that found in the XB-70 could be realistically considered for a civil aircraft where smaller loads are encountered, and therefore smaller gearboxes and transmission elements could be used.

\section{Conclusions and Further Work}

In this paper, the authors have presented a quick overview of the history behind the development of the XB-70 Valkyrie, with an emphasis on the needs and benefits for the folding wingtips.

\section{Conclusions}

It is clear from historical sources that the folding wingtips have led to a reduction in fin area, enhanced directional stability at supersonic speeds, and increased lift performances by benefiting from more compression lift. The specific details of the hinge devices and actuation were then derived, as very little data is currently available. Using flight test reports and geometrical data sheets, the number, size, weight and actuation capabilities of the power hinges and motors were estimated. Each power hinge was found to weigh approximately $140 \mathrm{~kg}$, and are roughly equivalent to $30 \mathrm{~cm}$ sided cubes in size. The 32,000-to- 1 ratio of the power hinges allowed for a shaft rotating at approximately $8000 \mathrm{rpm}$ in order to output wingtip rotational speeds of $0.25 \mathrm{rpm}$. The extremely high bending moments, estimated as up to $700 \mathrm{kN}$.m during flight test, could therefore become easily manageable by a relatively small motor. An estimate of the weight penalty due to the additional power hinge mass was also compared to the fin weight savings using conventional aircraft fin surface densities. It was found that overall, the weight penalty and savings were equivalent, allowing for overall better performances and previously mentioned benefits of the folding wingtips.

The scalability of the folding device was assessed against a conventional civil aircraft. A set of wings were used to assess available design space at the hinge line situated at $17 \mathrm{~m}$ from the central line, to respect airport size limitations. It was found that despite being too thin and short to house the XB70 actuation system, a similar approach could be scaled down, as different loads, flight conditions and wingtips are considered in this use case. If three power 
hinges or gear reduction systems were used in parallel instead of six, the effective loads per actuator would still half those encountered in the XB-70 for the larger wing variant, and less than a fifth for the baseline wing, thus allowing for significant downsizing possibilities of the system. Whilst not dismissing the idea of having lighter and more power dense solutions in SMA alternatives, this investigation shows that an electric motor and gearbox or power hinge combination as found on the XB-70 could be considered for short term applications due to their respective technology readiness level.

\section{Additional Discussion Points}

Nonetheless, the authors believe that a few additional statements should be made. First, it must be stated that maintenance requirements and life cycle expectations of the power hinges may be inadequate for viable commercial applications. This obviously was not an issue for the experimental military project, having been reduced to barely more than 200 cumulated flight hours throughout the program, but could be a potential show-stopper when applied to civil commercial aircraft. As military certifications strongly diverge from those used in the civil sector, what seemed acceptable for the XB-70 aircraft in terms of life cycle and maintenance implications may become unacceptable for our use case. Had the program gone through the experimental stages and into active service, a precious insight on the long-term use and maintenance of such devices would have been gained. Furthermore, a significant fin mass and area reduction was achieved by using folding wingtips on the XB-70. Such drastic changes should not be expected for the reasons already highlighted in Section 0 . Different configurations of commercial aircraft would benefit differently as moving the wingtips further aft (delta wing Concorde-like configurations) or forward (low swept HARW) would respectively increase and decrease the directional stability changes. In the case of the conventional tubular swept wing, wingtips being placed only slightly aft of the centre of lift and centre of gravity only yields a small increase in restoring yawing moment or stability as the longitudinal moment arm is so small. Furthermore, the wingtips on the XB-70 were, as previously outlined, the biggest movable surfaces ever designed and therefore, led to significant changes in vertical lift surface area when deflected.

\section{Further Work}

Significant challenges remain, as most of the results presented herein, extracted from enlightened assumptions and mathematical predictions, could greatly benefit from validation against real aircraft data. Interesting results could be highlighted by further investigating high gear reduction system similar to the Curtiss-Wright design for instance. To complete the sizing analysis for large civil aircraft applications, additional system sizing should also be carried out, including the sizing of hydraulic and electric actuators as a function of required torque for instance. Initial sizing methods for early design and prototype development stages were investigated by the authors concurrently to this work (Dussart et al., 2019). Non-conventional actuation such as Shape 
Memory Alloy (thermal or magnetic) and their scaling potential should also be investigated, as they could lead to lighter and more power dense solutions, as recently shown in the SAW project led by NASA and Boeing researchers (Kamlet \& Gibbs, 2018; Warwick, 2018). 


\section{References}

Ajaj, R., Flores, E. S., \& Friswell, M. (2013). Variable wing span using the compliant spar concept. 54th AIAA/ASME/ASCE/AHS/. Retrieved from http://arc.aiaa.org/doi/pdf/10.2514/6.2013-1451

Ajaj, R. M., Beaverstock, C. S., \& Friswell, M. I. (2015, January). Morphing aircraft: The need for a new design philosophy. Aerospace Science and Technology, 49, 154-166. https://doi.org/10.1016/j.ast.2015.11.039

Andrews, S. P. (2011). Modelling and simulation of flexible aircraft: Handling qualities and active load control. Cranfield University.

Barbarino, S., Bilgen, O., Ajaj, R. M., Friswell, M. I., \& Inman, D. J. (2011). A review of morphing aircraft. Journal of Intelligent Material Systems and Structures, 22(9), 823-877. https://doi.org/10.1177/1045389X11414084

Bourdin, P., Gatto, A., \& Friswell, M. I. (2008). Aircraft control via variable cant-angle winglets. Journal of Aircraft, 45(2), 414-423. https://doi.org/10.2514/1.27720

Bowman, J., Sanders, B., Cannon, B., Kudva, J., Joshi, S., \& Weisshaar, T. (2007). Development of next generation morphing aircraft structures. 48th AIAAASMEASCEAHSASC Structures Structural Dynamics and Materials Conference, (April), 1-10. https://doi.org/doi:10.2514/6.2007-1730

Bradley, M. K., Allen, T. J., \& Droney, C. K. (2014). Subsonic ultra green aircraft research: Phase II-volume III-truss braced wing aeroelastic test report. Retrieved from http://www.sti.nasa.gov

Bye, D., \& McClure, P. (2007). Design of a morphing vehicle. In 48th AIAA/ASME/ASCE/AHS/ASC Structures, Structural Dynamics, and Materials Conference. Reston, VA: American Institute of Aeronautics and Astronautics. https://doi.org/10.2514/6.2007-1728

Campanile, L. F. (2005). Initial thoughts on weight penalty effects in shapeadaptable systems. Journal of Intelligent Material Systems and Structures, 16(1), 47-56. https://doi.org/10.1177/1045389X05046692

Castrichini, A., Hodigere Siddaramaiah, V., Calderon, D. E., Cooper, J. E., Wilson, T., \& Lemmens, Y. (2016). Nonlinear folding wing tips for gust loads alleviation. Journal of Aircraft, 53(5), 1391-1399. https://doi.org/10.2514/1.C033474

Cheung, R. C., Castrichini, A., \& Cooper, J. E. (2017). Testing of wing-tip spring device for gust loads alleviation. In 58th AIAA/ASCE/AHS/ASC Structures, Structural Dynamics, and Materials Conference. Reston, 
VA: American Institute of Aeronautics and Astronautics. https://doi.org/10.2514/6.2017-0630

Cheung, R. C. M., Rezgui, D., Cooper, J. E., \& Wilson, T. (2018). Testing of a hinged wingtip device for gust loads alleviation. Journal of Aircraft, 55(5), 2050-2067. https://doi.org/10.2514/1.C034811

Cheung, R. C., Rezgui, D., Cooper, J. E., \& Wilson, T. (2019). Testing of folding wing-tip for gust load alleviation in high aspect ratio wing. In AIAA Scitech 2019 Forum. Reston, VA: American Institute of Aeronautics and Astronautics. https://doi.org/10.2514/6.2019-1863

Davies, P. E. (2018). North American XB-70 Valkyrie. London, England: Bloomsbury Publishing.

Dussart, G., Portapas, V., Pontillo, A., \& Lone, M. (2018). Flight dynamic modelling and simulation of large flexible aircraft. In Flight Physics Models, Techniques and Technologies. InTech. https://doi.org/10.5772/intechopen.71050

Dussart, G. X., Lone, M. M., \& O'Rourke, C. (2019). Size estimation tools for conventional actuator system prototyping in aerospace. In AIAA Scitech 2019 Forum. Reston, VA: American Institute of Aeronautics and Astronautics. https://doi.org/10.2514/6.2019-1634

Dussart, G. X., Yusuf, S. Y., \& Lone, M. M. (2018). Effect of wingtip morphing on the roll mode of a flexible aircraft. In 2018 AIAA/ASCE/AHS/ASC Structures, Structural Dynamics, and Materials Conference. Reston, VA: American Institute of Aeronautics and Astronautics. https://doi.org/10.2514/6.2018-1683

Hartl, D. J., \& Lagoudas, D. C. (2007). Aerospace applications of shape memory alloys. Proceedings of the Institution of Mechanical Engineers, Part G: Journal of Aerospace Engineering, 221(4), 535552. https://doi.org/10.1243/09544100JAERO211

Hayes, D., Lone, M. M., Whidborne, J., \& Coetzee, E. (2017). Evaluating the rationale for folding wing tips comparing the exergy and breguet approaches. In 55th AIAA Aerospace Sciences Meeting. https://doi.org/10.2514/6.2017-0464

Jenkins, D. R., \& Landis, T. (2002). North American XB-70A Valkyrie. Specialty Press. Retrieved from https://books.google.co.uk/ books?id=BRTHeWVY05oC\&dq=XB-70 valkyrie steve pace $\&$ hl $=$ fr\&source $=\mathrm{gbs} \_$similarbooks

Jenkins, J. M., DeAngelis, V. M., Friend, E. L., \& Monaghan, R. C. (1969). Flight measurments of canard loads, canard buffeting, and elevon and wing-tip hinge moments on the XB-70 aircraft including comparions 
with predictions. Washingto D.C.: NASA. Retrieved from https://www.nasa.gov/centers/dryden/pdf/87763main_H-554.pdf

Kamlet, M., \& Gibbs, Y. (2018). NASA tests new alloy to fold wings in flight. Retrieved January 30, 2018, from https://www.nasa.gov/centers/ armstrong/feature/nasa-tests-new-alloy-to-fold-wings-in-flight.html

Kota, S., Osborn, R., Ervin, G., Maric, D., Flick, P., \& Paul, D. (2006). Mission adaptive compliant wing - Design, fabrication and flight test. Retrieved from https://www.sto.nato.int/publications/.../RTO-MPAVT-168/MP-AVT-168-18.pdf

McGowan, A.-M. R., Vicroy, D. D., Busan, R. C., \& Hahn, A. S. (2009). Perspectives on highly adaptive or morphing aircraft. RTO Applied Vehicle Technology Panel (AVT) Symposium, 1-1-1-14.

Min, Z., Kien, V. K., \& Richard, L. J. Y. (2010). Aircraft morphing wing concepts with radical geometry change. The IES Journal Part A: Civil \& Structural Engineering, 3(3), 188-195. https://doi.org/10.1080/19373261003607972

NASA Glenn Research Center. (2018). NASA uses shape memory alloys to fold F-18 wing - YouTube. Retrieved January 29, 2019, from https://www.youtube.com/watch?v=RgpuReoirzk

Pace, S. (1990). North American XB-70 Valkyrie. Aero. Retrieved from https://books.google.co.uk/books?id=Z2NWAAAACAAJ\&dq=XB70+valkyrie+steve + pace $\&$ hl $=$ fr \&sa $=X \& v e d=0 a h U K E w j i z K 78 h a H a A h$ XKKcAKHcSaCmMQ6AEIJzAA

Peel, L. D., Mejia, J., Narvaez, B., Thompson, K., \& Lingala, M. (2009). Development of a simple morphing wing using elastomeric composites as skins and actuators. Journal of Mechanical Design, 131(9), 091003. https://doi.org/10.1115/1.3159043

Previtali, F. (2015). Morphing wing based on compliant elements. https://doi.org/10.3929/ethz-a-010546627

Ross, J., \& Rogerson, D. (1983). XB-70 technology advancements. In Aircraft Prototype and Technology Demonstrator Symposium. Reston, VA: American Institute of Aeronautics and Astronautics. https://doi.org/10.2514/6.1983-1048

Seigler, T. M. (2005). Dynamics and Control of morphing aircraft. Blacksburg, VA:Virginia Polytechnic Institute and State University. Retrieved from https://pdfs.semanticscholar.org/ 59e1/32d3eff25b18100bb67fd4832bac65643fcd.pdf

Seigler, T., Bae, J., \& Inman, D. (2004). Flight control of a variable span 
cruise missile. ASME 2004. Retrieved from

http://proceedings.asmedigitalcollection.asme.org/proceeding.aspx?arti cleid $=1652250$

Seigler, T. M., Neal, D. A., Bae, J.-S., \& Inman, D. J. (2007). Modeling and flight control of large-scale morphing aircraft. Journal of Aircraft, 44(4), 1077-1087. https://doi.org/10.2514/1.21439

Thill, C., Etches, J., Bond, I., Potter, K., \& Weaver, P. (2008). Morphing skins. Aeronautical Journal. https://doi.org/3216

Ursache, N. M., Melin, T., Isikveren, A. T., \& Friswell, M. I. (2008). Technology integration for active poly-morphing winglets development. Smart Materials, Adaptive Structures and Intelligent Systems, Volume 1, 775-782. https://doi.org/10.1115/SMASIS2008496

Warwick, G. (2018). NASA says wing-folding in flight saves fuel. Aviation Week \& Space Technology. Retrieved from http://aviationweek.com/ future-aerospace/nasa-says-wing-folding-flight-saves-fuel

Weisshaar, T. (2006). Morphing aircraft technology-new shapes for aircraft design. Multifunctional Structures / Integration of Sensors and Antennas, O1-1 - O1-20. https://doi.org/10.14339/RTO-MP-AVT-141

Wilson, T., Castrichini, A., Azabal, A., Cooper, J. E., Ajaj, R., \& Herring, M. (2017). Aeroelastic behaviour of hinged wing tips. In International Forum on Aeroelasticity and Structural Dynamics IFASD (pp. 1-18). Retrieved from https://imperiallondon.sharepoint.com/sites/ aeroelastics/Shared Documents/IFASD 2017 - Papers/IFASD-2017216.pdf 